\title{
NARRATIVAS, ATIVIDADES E PRÁTICAS NA FORMAÇÃO DOCENTE PARA A CULTURA DIGITAL
}

\author{
Lauro Roberto Lostada ${ }^{1}$ \\ Dulce Márcia Cruz ${ }^{2}$
}

\begin{abstract}
Resumo: Este trabalho tem como objetivo investigar a relação entre as narrativas, as atividades propostas e as realizadas no Curso de Especialização em Educação na Cultura Digital. As análises aqui apresentadas referem-se a um estudo documental, a partir do qual se pôde fazer uma análise dos conteúdos de cada um dos módulos do curso, bem como das atividades propostas e realizadas pelos cursistas ao longo de sua trajetória de estudos. Os elementos que serão apresentados no trabalho possibilitam o debate sobre a necessidade de uma formação para além da tessitura tradicional do conhecimento, cujo alicerce se constitui sobre a palavra escrita; apontando para a necessidade de se consolidar um projeto educacional dialógico, reflexivo e crítico, que permita o encontro entre os professores como forma de alicerçar um movimento permanente em vista do conhecimento das múltiplas formas de escrita do mundo contemporâneo.
\end{abstract}

Palavras-chave: Educação a Distância; Cultura Digital; Formação Docente.

\section{NARRATIVES, ACTIVITIES AND PRACTICES IN TEACHING TRAINING FOR DIGITAL CULTURE}

\begin{abstract}
This work aims to investigate the relationship between the narratives, the activities proposed and those carried out in the Specialization Course in Education in Digital Culture. The analyzes presented here refer to a documentary study, from which one could make an analysis of the contents of each of the modules of the course, as well as the activities proposed and carried out by the trainees throughout their study trajectory. The elements that will be presented in the work allow the debate on the need for a formation beyond the traditional knowledge structure, whose foundation is constituted over the written word; pointing to the need to consolidate a dialogical educational project, reflective and critical, that allows the meeting between teachers as a way of establishing a permanent movement in view of the knowledge of the multiple forms of writing in the contemporary world.
\end{abstract}

Keywords: Distance Education; Digital Culture; Teacher Training.

\footnotetext{
${ }^{1}$ Doutorando em Educação pela Universidade Federal de Santa Catarina, mestre em Educação pela Universidade Federal de Santa Catarina - UFSC, especialista em Mídias na Educação pela Universidade Federal do Rio Grande do Sul - UFRGS, especialista em Práticas Pedagógicas Interdisciplinares pelo Centro Universitário FACVEST, graduado e licenciado em Filosofia pela Universidade Federal de Santa Catariana - UFSC. É servidor público estadual da Secretaria de Estado da Educação de Santa Catariana, atuando na Escola de Educação Básica Irmã Maria Teresa como Assistente Técnico Pedagógico.

${ }^{2}$ Professora Associada do Departamento de Metodologia de Ensino (MEN), da Universidade Aberta do Brasil (UAB) e da Pós-Graduação em Educação do Centro de Ciências da Educação (PPGE/CED) da Universidade Federal de Santa Catarina (UFSC). Líder do grupo de Pesquisa EDUMIDIA - Educação, Comunicação e Mídias (CNPq). Bolsista Produtividade CNPq. Graduada em Comunicação Social (FAAP/SP), Mestre em Sociologia Política (UFSC), Doutora em Engenharia de Produção (UFSC).
} 


\section{INTRODUÇÃO - UM CENÁRIO DE MUDANÇAS}

Enquanto representante de uma tradição escolástica fundamental à manutenção de um complexo cenário histórico, a escola acabou privilegiando durante toda a sua trajetória a leitura da palavra escrita em seus processos pedagógicos. Diante das novas relações advindas da pós-modernidade e, especificamente, das tecnologias, tornou-se necessário aprender a ler todas as possibilidades performáticas de linguagem (oral, escrita, sonora e imagética), pois os novos processos de comunicação exigem um sujeito cada vez mais crítico e ágil em seu raciocínio, capaz de fazer escolhas e posicionar-se, construindo conceitos (DELEUZE e GUATTARRI, 1992).

A agilidade tornou-se gradualmente uma questão presente em nossa sociedade, de modo que "os rápidos ganham. Pessoas e empresas lentas ficam para trás. Nada mais dura para sempre" (BAUMAN, 2004). Deste modo, a fluidez interfere diretamente na constituição da identidade do sujeito pós-moderno, que se vê forçado a flutuar num espaço pouco definido para o qual a formação tradicional não o preparava. Novas competências são exigidas, de modo que não basta mais a mera identificação de signos linguísticos. Cada vez mais é necessário também a compreensão e a apropriação do significado das mensagens, o que exige um emaranhado de operações cognitivas que possibilitam ao sujeito selecionar, organizar, interpretar e reelaborar as mensagens que recebe sob diversos tipos de linguagem (LUCKESI, 1987).

\footnotetext{
A leitura do mundo precede a leitura da palavra, daí que a posterior leitura desta não possa prescindir da continuidade da leitura daquele. A linguagem e a realidade se prendem dinamicamente. A compreensão do texto a ser alcançado por sua leitura crítica implica a percepção das relações entre o texto e o contexto (FREIRE, 1988, p.10-12).
}

Ao analisar o trabalho de Margaret Mead, Martín-Barbero (2004) afirma que as dificuldades que enfrentamos para lidar com a mudança advêm de três modalidades culturais, a saber, a pós-figurativa (onde a cultura é transmitida de geração para geração e, portanto, o passado dos adultos constitui-se como o futuro das novas gerações), a configurativa (onde a conduta dos contemporâneos é que determina a formação das novas gerações), e, por fim, a pré-figurativa (onde os pares substituem os pais). Para o autor, estamos vivendo um momento que instaura uma verdadeira ruptura generacional, pois o aprendizado passa a ser menos fundado na dependência dos adultos que na própria exploração que os jovens fazem do novo mundo tecnocultural que os envolve 
(MARTÍN-BARBERO, 2004). Assim, diante do impasse gerado entre a tradição e a inovação proposta pelo novo momento social, a educação vive uma verdadeira crise, de modo que Martín-Barbero (2004, p. 339) questiona:

O que sabem nossas escolas, e inclusive nossas faculdades de educação, sobre as profundas modificações na percepção do espaço e tempo que vivem os adolescentes, inseridos em processos vertiginosos de desterritorialização da experiência e da identidade, e capturados numa contemporaneidade que confunde os tempo, debilita o passado e exalta o não-futuro fabricando um presente contínuo: feito por sua vez das descontinuidades de uma atualidade cada dia mais instantânea, e do fluxo incessante e embriagador de informações e imagens?

Sem saber como operacionalizar a mudança em tempos tão fugazes a escola segue relutante, produzindo e aumentando uma profunda lacuna entre aquilo que os jovens vivenciam e o que aprendem em suas salas de aula, deixando-os, portanto, indefesos ante as novas tecnologias, e impedindo que delas possam se apropriar de forma crítica e criativa (MARTÍN-BARBERO, 2004). Desse modo, a escola acaba preservando o saber como fonte de poder e, neste sentido, conserva a autoridade através do uso de suportes que, em geral, acabam caracterizando a relação entre a comunicação e a educação por um perfil essencialmente instrumental. As mídias passam a ocupar certo espaço na escola contemporânea apenas como "uma possibilidade de tornar o ensino menos entediante, de amenizar as jornadas presas a uma inércia insuportável" (MARTÍN-BARBERO, 2004, p. 314). De modo geral, a reação da escola diante das mídias e de um aluno repleto de informações, recebidas por todos os lados, diuturnamente, é de um entrincheiramento em seu próprio discurso e práticas. Assim, “enquanto o ensino percorre o âmbito do livro, o professor se sente forte, mas quando aparece o mundo da imagem o professor balança, a terra se move: porque o aluno sabe muito mais e, sobretudo, maneja melhor as linguagens da imagem que o professor" (MARTÍN-BARBERO, 2004, p. 343).

O que todo esse cenário apresenta é a necessidade de uma reforma educacional que possa dar conta de uma segunda alfabetização, justamente aquela ligada às múltiplas leituras que hoje conformam o mundo das mídias, inundando de informações os jovens. As mudanças nos processos de leitura indicam, portanto, a necessidade de uma articulação entre os diversos modos de ler o mundo, seja ele textual ou hipertextual. 
Poderíamos afirmar, diante de tudo o que já dissemos, que a escola tradicional segue em crise, pois, trata-se de uma instituição que só pode preencher sua função de inculcação e reprodução enquanto é mantida a adequação entre a mensagem pedagógica e a aptidão dos receptores em decifrá-la. Deste modo, podemos compreender que a possibilidade de mudança passa necessariamente pela promoção de novos valores, resultando na necessidade de se avaliar e rever as práticas pedagógicas tradicionais, muitas delas ainda pautadas exclusivamente no livro, para que gerem um novo modelo de educação e, por consequência, também de sociedade e de indivíduo.

Assim, cabe ao professor a competência de saber equilibrar em seu trabalho tanto os processos de "organização" quanto também os de "provocação"; afinal, ambos são fundamentais para promover uma lógica dentro do caos de informações que as tecnologias proporcionam aos indivíduos. É necessário, portanto, conscientizar os professores através de uma formação de qualidade sobre a importância da educação para o mundo moderno e de como ele precisa verificar em sua prática docente as tendências contemporâneas e as possibilidades efetivas que as tecnologias podem fornecer para a formação das novas gerações.

Talvez, sobre este aspecto, possamos dizer que o ponto central da questão que estamos discutindo esteja ainda nos próprios educadores, na transformação da cultura da escola e na possibilidade de que os educadores se apropriem dela. Há uma relação intricada entre a cultura da colaboração e a mudança educacional que aguardamos e, portanto, se não houver uma alteração na cultura docente, também não haverá no sistema educacional, ou seja, se a escola não se tornar mais eficaz, o sistema não poderá a tornar eficiente, de fora, indiscriminadamente.

Os professores são personagens fundamentais para a mudança da educação e não há melhora na escola sem a participação dos professores. Como afirma Zagury (2006), o método e as técnicas de ensino podem ser mudados por outras mais modernas, sem que isso melhore a educação, porque não é o método que faz um bom professor, mas é o professor que faz o método tornar-se efetivo e funcional. Deste modo, o que pode ser mudado são as práticas, as convicções e as crenças, tornando os professores verdadeiros especialistas em mudança e agentes midiáticos. 


\section{CULTURA DOCENTE E INOVAÇÃO}

A cultura docente é patrimônio simbólico que congrega os professores enquanto um coletivo, dando sentido à sua ação educativa. Assim sendo, a cultura docente expressa um conjunto de atitudes que norteiam a ação pedagógica do professor, influenciando as interações no espaço escolar. Segundo Gómez (1998), nas situações de incerteza e conflito é a cultura coletiva que dá suporte, significado, abrigo e identidade ao professor. Especificamente, Hargreaves (2001) diz que a cultura docente pode ser caracterizada por quatro grandes formatos: o individualismo, a colegialidade artificial, a balcanização e a colaboração. Assim, o individualismo seria, para o autor, a forma predominante nas escolas, cuja característica seria o isolamento do professor em sala de aula. Na cultura da colegialidade forçada ou artificial predominaria um conjunto de procedimentos desenvolvidos pela própria escola ou por outros organismos exteriores a ela para que os professores se agreguem em suas atividades. Na cultura da balcanização, por sua vez, identificamos a formação de pequenos grupos de professores no interior da escola, isolados entre si. Por último, na cultura de colaboração as relações são voluntárias, não impostas, emergentes, portanto, dos próprios professores e de seus interesses naturais.

Diante do caráter fugaz do mundo contemporâneo, a ressignificação mais eficiente da prática docente é possível através do desenvolvimento de formas de relacionamento mais colaborativas, o que significa dizer que a mudança no âmbito da educação não pode ser resultado de ações isoladas e individuais, forçadas, eventualmente; ao contrário, ela deve envolver o engajamento voluntário do professor numa ação solidária, construída na interação e nas trocas.

Como diz Fernandes (2000), contudo, os professores sentem necessidade de operacionalizar o significado da mudança, por isso, é compreensível que os docentes não resistam às mudanças apenas por resistir, simplesmente. Eles sentem a necessidade de aprender sobre as situações de ensino diferentes das até então experimentadas; querem conhecer as propostas de trabalho, seus pressupostos filosóficos, políticos e pedagógicos, para então adotá-las em suas atividades. Em geral, esse é um processo exigente, que reclama tempo, esforço, dedicação, investimentos e apoio institucional. 
Em vista da promoção da cultura digital na educação brasileira foi oferecido o Curso de Especialização em Educação na Cultura Digital a educadores atuantes nas redes de ensino público de todo o país, tendo como objetivo formá-los para integrar crítica e criativamente as tecnologias digitais aos currículos escolares. O curso foi um projeto de formação continuada que teve como meta constituir um diálogo ativo na busca por mudanças de paradigma na educação; para tanto, ele se organizou com base no compartilhamento de experiências que exploram, demonstram e analisam as possibilidades criativas da integração das Tecnologias Digitais de Informação e Comunicação (TDIC) aos currículos escolares.

Em Santa Catarina, a Universidade Federal de Santa Catarina foi a instituição encarregada da oferta de 800 vagas para o curso na modalidade a distância disponibilizadas para instituições das redes municipais e da rede estadual, com limite de até 100 escolas para cada rede. Embora o curso fosse planejado na modalidade a distância, ele também previa até $20 \%$ da carga horária na modalidade presencial, a ser realizada nas escolas e na própria UFSC. Poderiam se inscrever os educadores que estivessem nas funções de professores, gestores ou formadores de núcleos de tecnologia.

Quanto à organização do projeto, em geral, o curso era dividido em um Plano de Ação Coletivo, Núcleos Comuns e diversos outros Núcleos Específicos de Estudo. O Plano de Ação Coletivo, denominado como PLAC, era a espinha dorsal da proposta metodológica do curso, de modo que suas atividades tinham o objetivo de apontar caminhos possíveis para a ação docente. Já os Núcleos de Estudo tinham como meta a problematização e a reflexão do cotidiano da escola, sendo o seu maior diferencial a inclusão da discussão a respeito da integração das tecnologias digitais ao ensino das disciplinas e de seus conteúdos específicos.

Os materiais didáticos do cursos seriam distribuídos aos cursistas exclusivamente em formato de documentos digitais, hipertextuais em diversos suportes midiáticos (vídeos, textos, animações, entre outros) e estariam disponibilizados em um Ambiente Virtual de Ensino e Aprendizagem: o ambiente e-Proinfo (http://eproinfo.mec.gov.br/), mantido pelo próprio MEC. Atualmente ainda é possível o acesso de todo o material do curso no sítio www.educacaonaculturadigital.mec.gov.br. 
Para analisar o projeto em relação ao seu objetivo inicial, os pesquisadores primeiro realizaram um acesso aos diversos módulos do curso, de modo que a análise deste quadro inicial permitiu traçar um mapa cartográfico dos conteúdos propostos no Curso de Especialização em Educação na Cultura Digital. Assim, basicamente, podemos afirmar que o Curso teve sua estrutura desenvolvida em torno das seguintes possibilidades narrativas:

1. Texto: Fundamentado na narrativa textual, sem suportes visuais;

2. Vídeo: Fundamentado na narrativa visual;

3. Áudio: Fundamentado na narrativa de áudio, sem suportes visuais;

4. Entrevista: Fundamentado na narrativa audiovisual, baseia-se em entrevistas com atores sociais;

5. Documentário: Fundamentado na narrativa audiovisual, baseia-se em documentários longos, temáticos;

6. Hiperlink: Fundamentado na narrativa visual, resume-se em conjuntos imagéticos que direcionam para outras narrativas, sejam elas textuais, visuais ou audiovisuais;

7. Fluxograma: Fundamentado na narrativa visual, consta de esquemas ou mapas conceituais;

8. Slideshow: Fundamentado na narrativa visual, é uma sequência de imagens que se resumem numa apresentação animada;

9. Infográfico: Fundamentado na narrativa visual, é uma apresentação de informações com preponderância de elementos gráfico-visuais integrados em textos sintéticos e/ou dados numéricos;

10. Tutorial: Fundamentado na narrativa visual, resume-se num material de apoio para uso de outra narrativa;

11. Nuvem de palavras: Fundamentado na narrativa visual, é um esquema visual com palavras que visa resumir alguma discussão ou coletânea;

12. Cordel: Fundamentado na narrativa visual, preconiza a integração do texto com elementos estéticos da poesia e da arte gráfica;

13. Quiz: Fundamentado na narrativa visual, utiliza da arte gráfica para propor exercícios práticos;

14. Questionário: Fundamentado na narrativa textual, tem o objetivo de fixar conteúdos de forma mais elaborada que no quis;

15. Prezi/Apresentação: Fundamentado tanto na narrativa visual quanto na textual, apresenta informações sobre determinado assunto de forma a resumi-lo; 
16. HQ: Fundamentado na narrativa visual, apresenta uma história fictícia com informações textuais que tendem a informar;

17. Game: Fundamentado na narrativa audiovisual, tem como objetivo a informação ou elaboração de competências através de estratégias e desafios;

18. Tabelas: Fundamentado na narrativa visual, condensa informações textuais;

19. Tour $360^{\circ}$ : Fundamentado na narrativa visual, possibilita a imersão do cursista num cenário, como se lá estivesse;

20. Charge: Fundamentado na narrativa visual, une texto e imagem para a exposição de uma situação geradora;

21. Animação: Fundamentado na narrativa visual, transpõe a hq por utilizar das possibilidades gráficas da animação;

22. Imagem: Fundamentado na narrativa visual, tem como meta a ilustração de um texto, apresentando cenas ou imagens que servem para tornar mais atrativo o material.

O quadro geral das possibilidades narrativas encontradas no desenvolvimento do Curso pode ser resumido da seguinte forma:

Gráfico 1: Elementos Narrativos do Curso de Especialização - Eixo Conteúdo

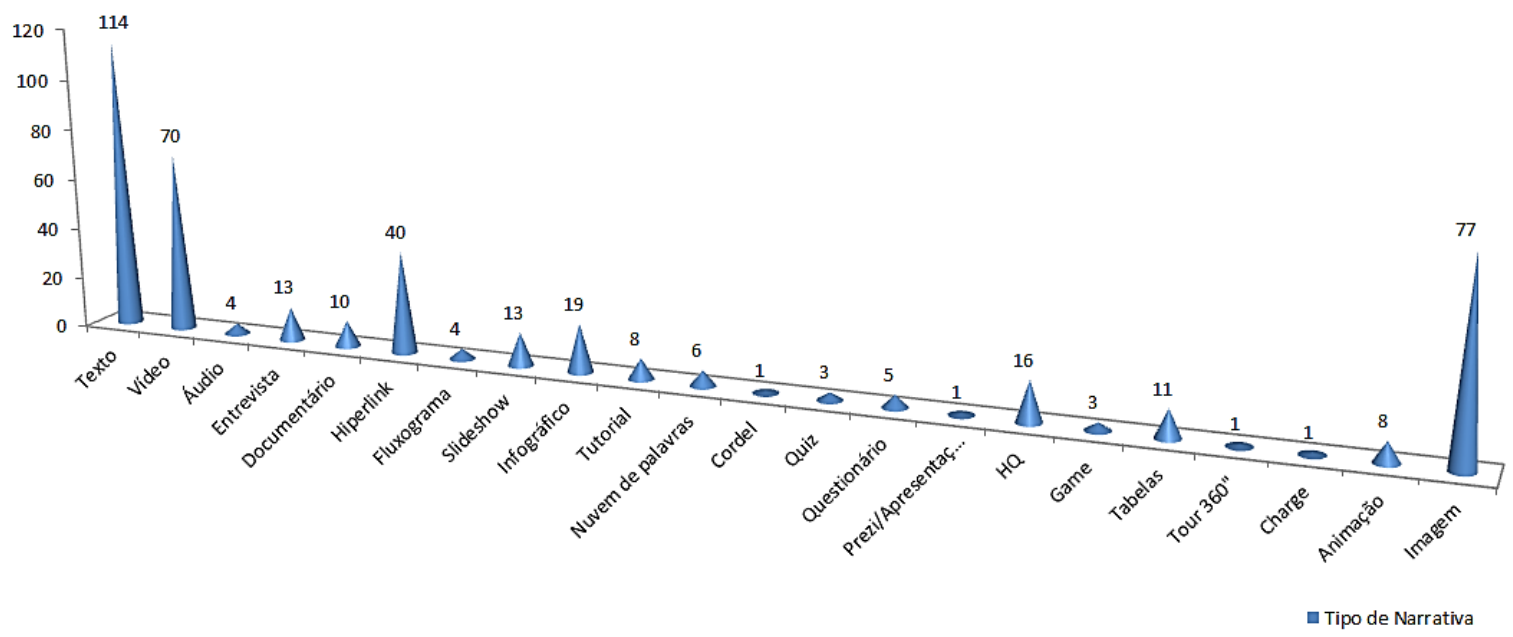

Fonte: Dos autores (2017)

Uma análise mais detalhada dos elementos que compõe o curso, nos seus diversos núcleos de estudo, permite apontar que, apesar da intenção de constituir um diálogo ativo na busca por mudanças de paradigma na educação, oferecendo uma formação apoiada no compartilhamento de experiências que exploram, demonstram e analisam as possibilidades criativas da integração das tecnologias digitais aos currículos 
escolares, o curso se estruturou, no tocante aos conteúdos, a partir de quatro grandes eixos narrativos, a saber: o texto, a imagem, o vídeo e o hiperlink.

$\mathrm{O}$ avanço didático proposto para o projeto acabou não sendo realizado e os nortes narrativos que talvez evidenciassem uma mudança na perspectiva tradicional de ensino-aprendizagem desenvolvido no curso acabaram sendo pouco explorados nos diversos módulos. A estrutura do projeto permaneceu, portanto, vinculada em torno do poder/saber docente, sendo os elementos narrativos utilizados apenas como atrativos para uma aula baseada fundamentalmente no livro-texto (MARTÍN-BARBERO, 2004).

Confirmando tal perspectiva, abaixo podemos visualizar alguns gráficos onde encontramos exemplos da falta de variação narrativa. Observe:

Gráfico 2: Exemplos de Elementos Narrativos por Módulo Temático - Eixo Conteúdo JOGOS DIGITAIS

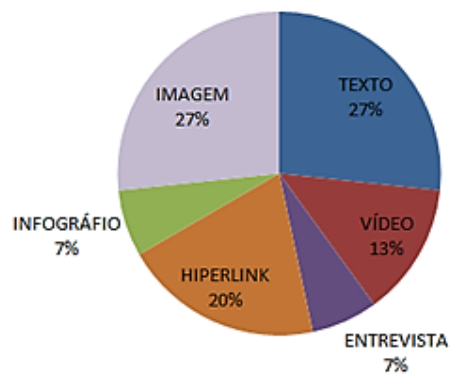

FORMAÇÃO DE ED. NA CULTURA DIGITAL

TECNOLOGIAS DIGITAIS

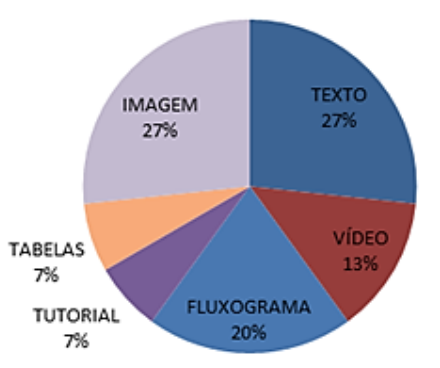

ARTES
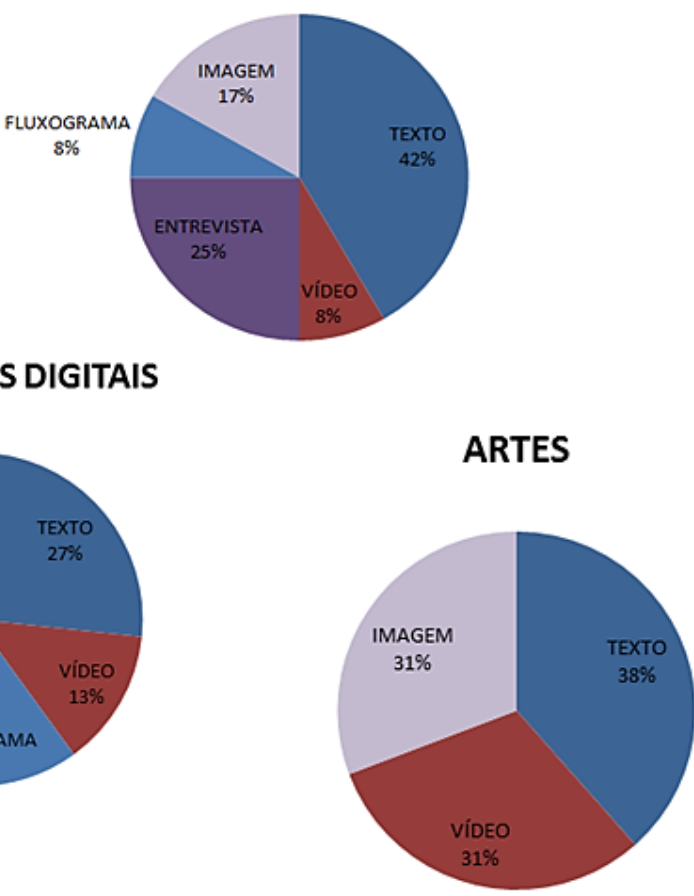

Fonte: Dos autores (2017)

Analisando os gráficos, podemos dizer que não há no módulo de Jogos Digitais quaisquer aplicações gamificadas do conteúdo apresentado, sendo todo o curso estruturado principalmente em torno de textos, imagens, vídeos e hiperlinks. Os únicos módulos que fizeram uso do recurso da gamificação, contrariamente ao que se poderia 
supor, foram o de Língua Portuguesa, Geografia e História. Da mesma forma, seguindo o padrão narrativo estabelecido ao longo do curso, podemos verificar também nos módulos de Formação de Educadores na Cultura Digital, Tecnologias Digitais e Artes, a manutenção de uma base metodológica centrada no texto, na imagem e no vídeo. Esse padrão, aliás, poderia ser apresentado em qualquer um dos outros módulos do curso, mas optamos por destacar apenas os gráficos desses quatro módulos, por considerá-los mais representativos em relação ao que se propunha com o projeto inicial do curso.

Num segundo momento da pesquisa, através de um perfil docente, passamos a analisar também as atividades solicitadas e aquelas realmente realizadas pelos alunos ao longo da sua formação. É importante esclarecer, contudo, que o curso oferecia uma série de atividades como "sugestões" aos professores responsáveis pela aplicação dos módulos; assim, esses professores tinham a liberdade de, juntamente com seus tutores, selecionar as atividades que considerassem mais pertinentes para aplicação com seus alunos. Deste modo, abaixo reproduzimos dois gráficos que permitem, em paralelo, traçar um comparativo entre as atividades que foram planejadas inicialmente para o curso e aquelas que foram efetivamente praticadas ao longo da formação. Observe primeiramente o gráfico com as atividades propostas:

Gráfico 3: Atividades Propostas para o Curso de Especialização em Educação na Cultura Digital

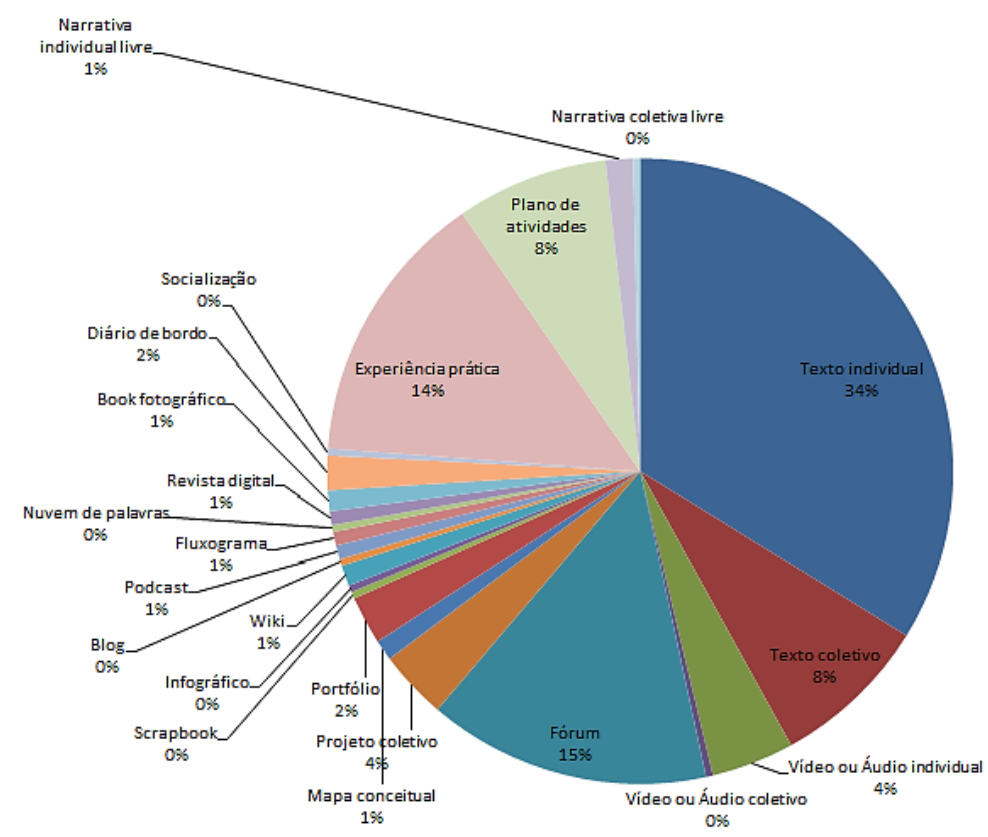

Fonte: Dos autores (2016). 
Observe agora também as atividades que foram efetivamente realizadas pelos cursistas ao longo de sua formação:

Gráfico 4: Atividades Realizadas no Curso de Especialização em Educação na Cultura Digital

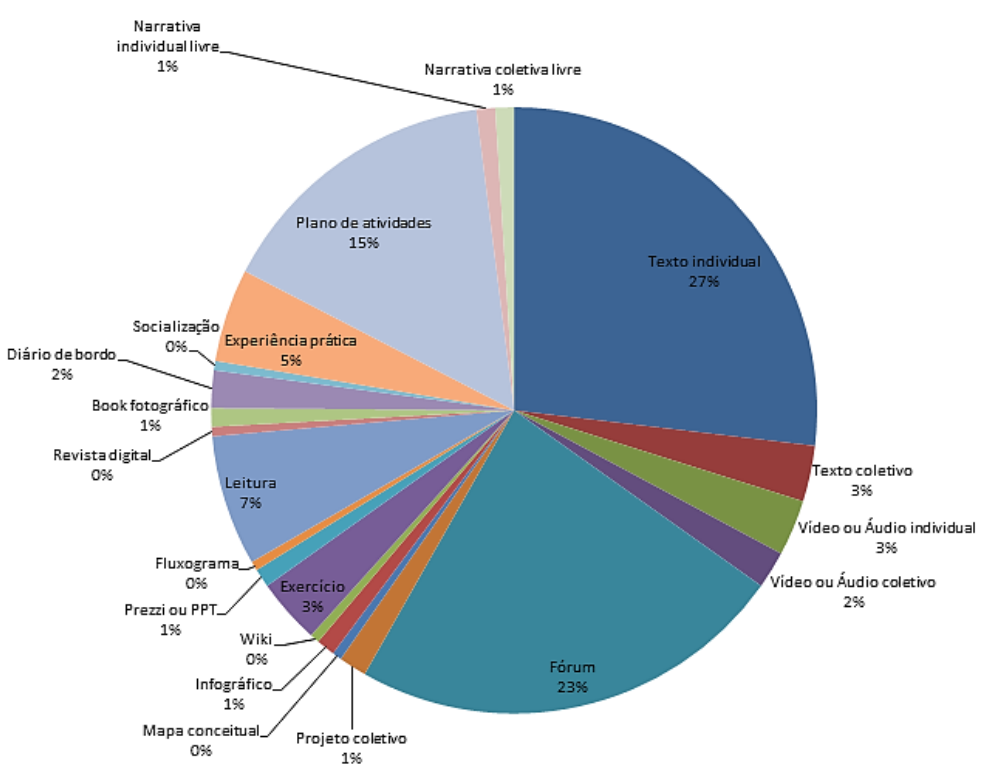

Fonte: Dos autores (2016).

Em geral, podemos resumir as atividades descritas nos gráficos acima da seguinte forma:

1. Texto individual: narrativa textual de cunho individual;

2. Texto coletivo: narrativa textual de cunho coletivo;

3. Vídeo ou Áudio individual: narrativa de vídeo ou áudio realizada individualmente;

4. Vídeo ou Áudio coletivo: narrativa de vídeo ou áudio realizada coletivamente;

5. Fórum: espaço para troca, debates e apresentação de ideias;

6. Projeto coletivo: construção coletiva de proposta de atividade prática;

7. Mapa conceitual: narrativa visual, com apresentação de esquemas conceituais;

8. Portfólio: espaço para alocação de materiais, biblioteca;

9. Scrapbook: é um livro de recortes, onde há personalização de fotos, resultando numa narrativa visual;

10. Infográfico: é uma apresentação de informações com preponderância de elementos gráfico-visuais e textos;

11. Wiki: é um conjunto de páginas integradas que podem ser editadas por qualquer pessoa, resultando num produto final de cunho coletivo; 
12. Blog: página web que possibilita a distribuição de informações, textos, imagens e vídeos;

13. Podcast: são programas de áudio, distribuídos em uma plataforma que permite o acesso público;

14. Fluxograma: é uma apresentação gráfica que permite a apresentação conceitual de forma resumida e mais acessível;

15. Nuvem de palavras: resumo de conceitos ou expressões resumo de uma narrativa textual;

16. Revista digital: revista em formato digital, sem custo, aberta ao acesso público pela web;

17. Book fotográfico: revista digital com coletânea de fotografias;

18. Diário de bordo: espaço para descrição de experiências, sentimentos, dificuldades e conquistas;

19. Socialização: atividade com objetivo de apresentar experiências a um grupo determinado;

20. Experiência prática: experiência prática para aplicação de conceitos e estratégias;

21. Plano de atividades: projeto de atividade prática potencialmente aplicável;

22. Narrativa individual livre: atividade narrativa livre de cunho pessoal;

23. Narrativa coletiva livre: atividade narrativa livre de cunho coletivo;

24. Leitura: atividade de leitura de material sugerido;

25. Assistir vídeo: atividade voltada à leitura de material audiovisual;

26: Prezzi ou PPT: construção de apresentação em programa prezzi, power point ou similar;

27. Exercício: atividade de exercício aplicado, especialmente voltado às ciências exatas.

A análise comparativa dos gráficos, por sua vez, permite dizer que, tanto quanto no seu eixo de conteúdo, o Curso se estruturou em relação às atividades também em torno de alguns poucos elementos narrativos, a saber: o texto individual, o fórum, a experiência prática e o plano de atividades. Em geral, o modelo do curso seguiu um parâmetro tradicional de formação docente, onde os estudantes desenvolveram boa parte de suas atividades de maneira isolada, fragmentada, com poucos momentos de socialização, na maioria das vezes caracterizados por uma colegialidade forçada. Assim, em resumo, a comparação entre aquilo que foi sugerido inicialmente e o que se praticou ao longo da formação demonstra a divergência metodológica de uma proposta 
que, por sua natureza, tenderia à multiplicidade de linguagens e estratégias narrativas. Observe, por exemplo, o caso do módulo de Formação de Educadores na Cultura Digital:

Gráfico 5: Atividades Propostas x Atividades Realizadas - Módulo Formação de Educadores na Cultura Digital

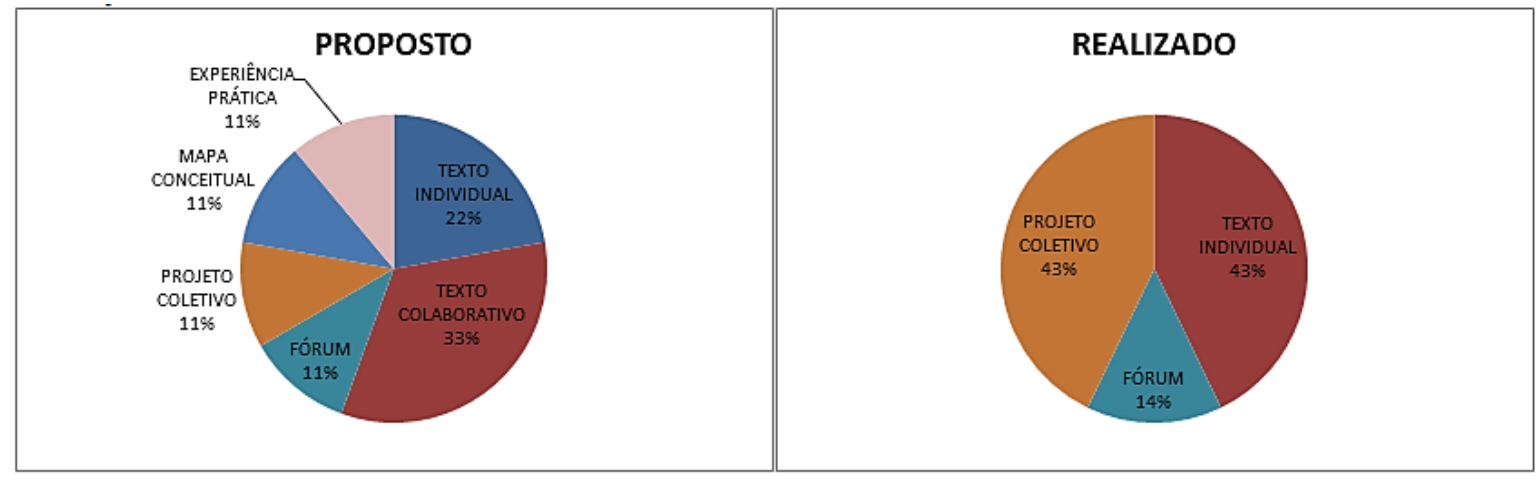

Fonte: Dos autores (2016)

É certo, contudo, que apesar da carência de elementos narrativos da cultura digital contemporânea, o curso seguiu como uma importante oportunidade para que os professores das redes de ensino repensassem colaborativamente suas práticas pedagógicas. Apesar de termos constatado através de nossas análises a reprodução de mecanismos de transposição didática que, seguindo os parâmetros tradicionais de formação, não permitem a formação para as múltiplas linguagens do mundo contemporâneo, podemos dizer que o curso, ainda sim, configurou-se como uma excelente oportunidade para que os professores, mais do que aprendessem a utilizar das tecnologias como instrumentais para uma melhor prática docente, pudessem se organizar coletivamente em vista de um objetivo comum.

O curso teve, portanto, grande importância no sentido de incentivar a cultura da colaboração docente ao organizar grupos de trabalhos em cada uma das escolas atingidas pelo projeto - a inscrição para o curso só era possível se houvessem no mínimo quatro professores e dois gestores interessados em participar do projeto na mesma unidade de ensino. Embora, portanto, tenhamos diagnosticado que o Curso não atingiu seu objetivo no fomento de competências docentes para a cultura digital, ele seguiu gerindo espaços de discussão nos ambientes escolares, com busca de alternativas para os problemas locais em vista da inclusão de uma nova cultura escolar, baseada na participação. 


\section{CONCLUSÃO}

O cenário contemporâneo evidencia uma verdadeira crise na educação, onde se estabelece um profundo abismo entre aquilo que as pessoas vivenciam e o que ensinam as escolas. Os professores reproduzem em suas práticas um modelo tradicional de ensino que se tece em torno do binômio saber/poder. Assim, os elementos narrativos da cultura digital são introduzidos nesse cenário de forma calculada, quase sempre apenas para tornarem mais atrativas as aulas, cujo fundamento persiste centrado na palavra escrita/proferida. Os alunos não são capacitados para a leitura das múltiplas linguagens, sendo avaliados pela mera reprodução dos conceitos apresentados. Não há, portanto, formação crítica e criativa.

O que se tem tornado latente é uma nova relação de forças que se traduzem numa complexa dinâmica de agenciamentos. A evolução das mídias tem gerado uma nova gama de elementos de escrita, possibilitando a agregação de múltiplos mecanismos digitais, que permitem grandes inovações na produção do conteúdo, no compartilhamento das informações e na criação de redes sociais. Assim sendo, diante das práticas escolares que persistem em reproduzir modelos acríticos de ensino, cujo sucesso se relaciona tão somente à mera capacidade de memorização, a formação de professores tem se mostrado uma necessidade em nossa sociedade.

Neste aspecto, o Curso de Especialização em Educação na Cultura Digital serve como referência de um projeto de formação continuada capaz de sensibilizar a docência para a formação crítica, colaborativa. $\mathrm{O}$ que se constatou com os dados apresentados neste trabalho é que o curso analisado não conseguiu superar o modelo tradicional, com a inclusão de novos elementos narrativos da cultura digital. A base da proposta de formação continuou sendo a palavra escrita e os novos elementos acabaram sendo incluídos enquanto transpostos didáticos, sem grandes revoluções.

Essa dificuldade de conceber novos modelos pedagógicos não se constituiu, porém, como declaração do fracasso do curso em questão, pois, ao contrário, as experiências que o projeto nutriu são a prova de que a escola está em processo de mudança, ao mesmo tempo em que os professores sentem a necessidade de mudar também. O curso em questão foi fundamental para a organização de um espaço de encontro entre professores, cujo resultado se expressa na constituição de uma cultura docente que fomenta o patrimônio simbólico compartilhado, o qual dá sentido à sua ação educativa, influenciando as interações no espaço escolar. 
A mudança a que se propunha o projeto, como um processo de ressignificação da prática, se tornou possível através do desenvolvimento de formas de relacionamento colaborativas, de forma que a inovação se constitui, assim, como o resultado de uma ação solidária, construída na interação e nas trocas.

\section{REFERÊNCIAS:}

BAUMAN, Zygmunt. Amor Líquido. São Paulo: Zahar, 2004.

DELEUZE, Gilles; GUATTARI, Félix. O que é filosofia? Trad. Bento Prado Jr. e Alberto Alonso Muñoz. Rio de Janeiro: Ed. 34, 1992.

FERNANDES, Margarida Ramires. Mudança e Inovação na Pós-modernidade: perspectivas curriculares. Porto, Portugal: Porto Ed., 2000.

FREIRE, Paulo. A Importância do ato de ler: em três artigos que se completam. São Paulo: Cortez, 1988.

GÓMEZ, Ángel I. Pérez. La cultura escolar em la sociedad neoliberal. In: FARIAS, Isabel Maria Sabino de. Repercussão das políticas educacionais na escola: inovação, mudança e cultura docente. GT: Estado e Política Educacional, nº 05, UECE, 1998.

HARGREAVES, Andy. O ensino como profissão paradoxal. Revista Pátio. Educação - agenda para o século XXI. Porto Alegre: ARTMED, Ano IV, nº 16, fev/abr de 2001.

KUHN, Thomas. A estrutura das Revoluções Científicas. São Paulo: Perspectiva, 1975.

LUCKESI, Cipriano, et al. O leitor no ato de estudar a palavra escrita. In: Fazer universidade: uma proposta metodológica. São Paulo: Cortez, 1987.

MARTÍN-BARBERO, Jesús. Ofício de cartógrafo: Travessias latino-americanas da comunicação na cultura. São Paulo: Edições Loyola, 2004.

MARTON, Scarlett. A terceira margem da interpretação: Müller-Lauter revisita Nietzsche. In: MARTON, Scarlett. Extravagâncias: Ensaios sobre a filosofia de Nietzsche. São Paulo: Discurso Editorial, 2009.

MENDES, Angelista de A. R. et al. A relação histórica da educação a distância com a inclusão social e o desenvolvimento das tecnologias de informação e comunicação. In: Anais do $1^{\circ}$ Encontro de Pós-Graduação em Educação da UNIR. Porto Velho - RO: EDUFRO, 2010.

ZAGURY, Tânia. O professor refém: para pais e professores entenderem porque. fracassa a educação no Brasil. Rio de Janeiro: Record, 2006. 
